\title{
Training Treatment Skill of Children Abuse Victims for College Students
}

\author{
A. R. Koesdyantho ${ }^{1 *}$ iD \\ ${ }^{I}$ Guidance and Counseling Program, Universitas Slamet Riyadi, Indonesia \\ *Corresponding author: roedykoes19@gmail.com
}

\begin{abstract}
Child abuse is a serious phenomenon that needs treatment to recover the victims. The problems occurred are the students are lack of understanding in giving treatments for child abuse victims, and they have no experience and skills in giving treatment to child as abuse victims. The present article aims at describing a training of giving treatments to recover children as victims from abuse and violence to show the students' (participants) knowledge and service before they do internship program at an orphanage in order to have knowledge and skills to give treatments for child abuse victims. The type of research is descriptive qualitative. The subject of research is 7th semester students of guidance and counseling, Indonesia. The methods in collecting the data used observation and a questionnaire. In analyzing the data, the researcher used interactive analysis that covers data display, data reduction, and conclusion drawing. The result of the research are the improvements of the college students' knowledge and service in giving treatment for child abuse victims; they are familiar with six forms of treatment to recover the victims that consist of Combined Parent-Child Cognitive Behavioral Therapy (CPC-CBT), Parent Training and Multi-systemic Therapy, Project Support (Children's Protective Services), Web-based parenting skills, Home Visiting Program, and School Based Mental Health Intervention for Children. So, are treatments in the form of collaboration between parents (caregivers), schools, and children (as victims) to recover child abuse and violence through a variety of phases to realize the purposes and children abuse as victims need appropriate treatment based on the condition of them and such six treatments as a choice and solution to recover the victims. The research is that the improvement of knowledge and skills of the students to give treatment for children as abuse victims.
\end{abstract}

Keywords: Child Abuse, Treatment Skill

\section{Introduction}

The phenomenon of a child as victims globally occurs until 1 billion children every year. The abuse mostly happens in punishment context (Ruiz-Casares et al., 2019). Meanwhile, the security of children in industrialized country is heavier than developing country, i.e. in Sub Sahara African, a child may 10 times to die before five age (Chan et al., 2016). Law has guaranteed for child protection, however it still needs involvement of community, family, non-government institutions, and all other parties for child's protection (Dendape et al., 2019). Parents' attitudes towards corporal punishment are the variables most closely related to all forms of violence against children. The risk of all forms of child abuse is also higher for boys, those who live with multiple household members and in poorer families (Akmatov, 2011). Child abuse is caused by some aspects. Child abuse is caused by violence in internet, computer, and a video game that shows example how to hurt someone (Damm, 2011). Unsuccessful education to educate characters to children is also a cause of that

$\begin{array}{lll}\text { History: } & & \text { Publisher: Undiksha Press } \\ \text { Received } & : 21 \text { December } 2020 & \text { Licensed: This work is licensed under } \\ \text { Revised } & : \text { 2 January } 2021 & \text { a Creative Commons Attribution 3.0 License } \\ \text { Accepted } & : \text { 16 January } 2021 & \text { CC OP OP } \\ \text { Published } & : 25 \text { February } 2021 & \end{array}$


phenomenon (Khoeriyah et al., 2018). Caregiver did child maltreatment because poor social support, domestic violence, mental health issues, and drug abuse issues were noted among abusive administrators (Taillieu et al., 2019). Financial problems (low economical level) and characteristics of perpetrators (youth, low levels of education, fall victim to neglect and abuse in childhood, aggressive personality, addiction to alcohol, medication or drugs, unemployment, an underdeveloped sense of responsibility and justice) are the causes of child abuse (Biçakçi et al., 2016).

There are variety types of child's abuse. studied different child abuse types: physical, sexual, emotional abuse, neglect and witnessing parental IPV (Rueness et al., 2019). There are many kinds of severe child maltreatment, i.e. physical abuse, sexual abuse, emotional abuse, physical neglect, emotional neglect, exposure to intimate partner violence (Afifi et al., 2012). In general, there are four types of child abuse: (Yoon, 2020) emotional or psychological abuse, physical abuse, sexual abuse and neglect (Akmatov, 2011). Categorized child abuse into four types: Friendly (with a prosocial peer group), socially neglected (with a group of prosocial partners), very anti-social friends' group, and moderate antisocial peer support group (Yoon, 2020). There are many effects of child abuse. Corporal punishment affects a child's level of antisocial behavior (Grogan-Kaylor, 2004). Farnia et al. (2020) study the effect of child abuse on behavioral problems and the results revealed a direct effect of child abuse on the behavioral problems in the children of parents with substance use disorder. Tsur \& Abu-Raiya (2020) state their result of research about the effect of experiencing child abuse to covid 19 fear and related stress and the result is that individuals with a child abuse history may have increased COVID-19 stress (i.e., fear of COVID-19 and COVID-19 ASD), through mediation of complex posttraumatic stress disorder (CPTSD) (which is a symptom of PTS and DSO). However, when controlling these mediation effects, the findings show that they are comparable for individuals who do not have a history of CA, CA owner can undergo stress COVID-19 down. Besides, O'Leary, Coohey, \& Easton (2010) studied to examine the relationship between adolescent sexuality, mental health abuse, disclosure, and symptoms in adulthood. The multivariate model shows that the respondents in PT The 30s and 40s were harassed by more than one perpetrator, namely harmed by perpetrators, who are biologically abused relatives, who told him about the position when it happened, and who had not discussed the harassment in the past year abuse has other mental health symptoms.

There are many solutions of solving child abuse to victims. A combination between parents and cognitive behavioral therapy for children is to treat child physical abuse as a study (Runyon et al., 2010). The implementation of Combined Parent-Child Cognitive Behavioral Therapy CPC-CBT resulted that parents and children in the group indicated higher improvement in total post-traumatic symptoms and positive parental skills compared to those who participated in the Parents Only-CBT (Runyon et al., 2010). Another form of CBT is Game-Based Cognitive-Behavioral Therapy (GB-CBT), Who teaches skills, process of trauma, assists children and their family employing structured therapeutic games and activities as main techniques(Springer \& Misurell, 2012). This study integrates between elements of Trauma Focused CBT that includes building of social skill, child sexual abuse psycho-education, training on personal safety skills, and exposure treatment with interventions of play therapy. Another solution is Parent Training and Multi-systemic Therapy. Multi-systemic therapy is a treatment based on evidence designed for youth with serious antisocial behavior and high risk for out of home and their families (Fonagy et al., 2020; Henggeler \& Schaeffer, 2016; Rogers \& Broome, 2020). The programme is intensive and family focused and helps young people manage their behaviour in various contexts, including at home, at school, and in the community (Fonagy et al., 2020). Multisystemic therapy is a promising intervention to improve the prognosis of antisocial and offending 
behaviour in young people (Markham, 2018). Project support is beneficial treatment to decrease maltreatment of children among families which has occurred (Jouriles et al., 2010).

The implementation of web-based parenting skills resulted that parents who get the parenting skill treatment show more positive parenting behaviors significantly (Mast et al., 2014). Home visit has important effects that covers training, supervising, and monitoring, particularly child maltreatment outcomes (Casillas et al., 2016). Finally, the implementation of intervention based school for reducing posttraumatic stress disorder symptoms, depressed and anxious feeling; and increasing hopes and functioning senses indicates that children living together with their parents indicated reduces in the aspects of posttraumatic stress disorder and depressive symptoms (Tol et al., 2015). The present article intends at describing a training of giving treatments to recover children as victims from abuse and violence to show the guidance and counseling students' knowledge and service before they do internship program at an orphanage.

\section{Materials and Methods}

The present article aims at showing a training of treatments to recover children as victims from abuse and violence. The subject of research is guidance and counseling students at Universitas Slamet Riyadi, Indonesia. There are six forms of treatment to recover them. They are Combined Parent-Child Cognitive Behavioral Therapy (CPC-CBT), Parent Training and Multi-systemic Therapy, Project Support (Children's Protective Services), Web-based parenting skills, Home Visiting Program, and School Based Mental Health Intervention for Children. The training consisted of two sessions that happened in two days, $2^{\text {nd }}$ and $4^{\text {th }}$ December. The materials for $1^{\text {st }}$ session are the phenomenon of child abuse in global and in Indonesia, a way of recovering a child as an abuse victim of, factors that cause child abuse, the effects of child abuse, the characteristics of child as victims of as well as talking about the strengths, and weaknesses of the six ways. The session focused on the students' knowledge and its measurement before and after the training. In the $2^{\text {nd }}$ session, the materials are reviewing the $1^{\text {st }}$ training at glance, showing some videos about the six ways of recovering the victims, telling the implementation of the six ways as well as practicing a simulation of the six ways. This session measured the students' service for child abuse victims before and after the training. The methods of collecting the data are observation and a questionnaire. Then, the method of analyzing the data is through interactive analysis that covers data display, data reduction, and conclusion. The questionnaires contained 10 questions each and they had to answer with yes or no. The questions consisted of their knowledge about a way to recover a child as victims of abuse, factors that cause child abuse, the effects of child abuse, the characteristics of child as victims of abuse; and Combined Parent-Child Cognitive Behavioral Therapy (CPC-CBT), Parent Training and Multi-systemic Therapy to recover a child as victims of abuse, Project Support (Children's Protective Services), Web-based parenting skills, Home Visiting Program, and School Based Mental Health Intervention for Children to recover a child as victims of abuse.

\section{Results and Discussion}

\section{The $1^{\text {st }}$ Meeting (Students' Knowledge)}

In the $1^{\text {st }}$ day $\left(1^{\text {st }}\right.$ session), the learning outcome is the students' knowledge about ways of giving treatment for child as abuse victims. Before starting the training, the trainer (as also a lecturer, Pak Rudi) gave greeting to the students, then they responded enthusiastically. He (assisted with some of his students) distributed a questionnaire about knowledge and service before delivering a presentation and giving a simulation of recovering a victim of child abuse. He began his presentation by talking about the phenomenon of child 
abuse in global and in Indonesia. He then told the participants about the meaning, characteristics, and classification of a treatment for child as an abuse victim. Subsequently, they explained about the strengths, and weaknesses of the six ways of recovering the victims. The students gave attention and wrote a note about his explanation. Before ending the $1^{\text {st }}$ session, he distributed a questionnaire to them to check and measured their knowledge about the materials having been presented.

The students' knowledge before training showed that there are only four participants who do not know about a way to recover a child as victims of abuse. Then, there are three participants who know factors that cause child abuse. Besides, there are three of them who know the effects of child abuse. Relating to their knowledge about the characteristics of child as victims of abuse, there are six of them who know. Then, there are no participant who know about Combined Parent-Child Cognitive Behavioral Therapy (CPC-CBT). Subsequently, there are two students who know about Parent Training and Multi-systemic Therapy to recover a child as victims of abuse. Meanwhile, there are no participants who know about Project Support (Children's Protective Services). There are five participants who know about Web-based parenting skills to recover a child as victims of abuse. Then there are seven participants who know about Home Visiting Program to recover a child as victims of abuse. Finally, there are no participants who know about School Based Mental Health Intervention for Children to recover a child as victims of abuse.

After training, he distributed a questionnaire. The results are that all participants know about a way to recover a child as victims of abuse, know factors that cause child abuse, know the effects of child abuse, know the characteristics of child as victims of abuse. There is one participant who do not know about Combined Parent-Child Cognitive Behavioural Therapy (CPC-CBT) and Parent Training and Multi-systemic Therapy to recover a child as victims of abuse. All of the participants know about Project Support (Children's Protective Services), Web-based parenting skills to recover a child as victims of abuse, and Home Visiting Program to recover a child as victims of abuse. Finally, there is still one participant who do not know about School Based Mental Health Intervention for Children to recover a child as victims of abuse

\section{The $2^{\text {nd }}$ Meeting (Simulation of Students' Service)}

The $2^{\text {nd }}$ of the training was held in $4^{\text {th }}$ November 2020 . The materials of the training are reviewing the $1^{\text {st }}$ training at glance, showing some videos about the six ways of recovering the victims, telling the implementation of the six ways, and practicing a simulation of Parent-Child Cognitive Behavioral Therapy, Parent Training and Multisystemic Therapy, Web-based parenting skills, Home Visiting Program, and School Based Mental Health Intervention. Before starting the training, He checked the readiness of a questionnaire for participants, LCD, and laptop for presentation. He began to train by greeting the participants and they responded enthusiastically. He then conveyed the materials of the training (written above) and told them about the objectives of the training, that they are able to use the six models after they graduate from this University and they are able to practice a simulation using one of the six models.

The results of a questionnaire before training are that there are five participants who are able to give information clearly about the ways to recover child whose gets abuse. Then there are three participants who are able to write clearly about the ways to recover child whose gets abuse. Subsequently, there are two participants who are able to practice to try to recover child whose gets abuse. Then, there are two participants who are able to prepare many things before doing to recover child whose gets abuse and to help parents who's their child gets abuse. There is one participant who are not able to show good attitude when recovering the child and to show good behavior when recovering the child. There are two 
participants who are not able to cooperate well with friends when recovering the child. Finally, there is one participant who is not able to guarantee that his/ her service to the child is standard (process and result) as well as one participant is not able to communicate with parents of the child and the child if they ask a question and give a critique.

Then, the results of the questionnaire after the training are that all of participants are able to give information clearly about the ways to recover child whose gets abuse, able to write clearly about the ways to recover child whose gets abuse, able to practice to try to recover child whose gets abuse, able to prepare many things before doing to recover child whose gets abuse, able to help parents whose their child gets abuse, able to show good attitude when recovering the child, able to show good behavior when recovering the child, able to cooperate well with friends when recovering the child, guarantee that their service to the child is standard (process and result), and able to communicate with parents of the child and the child if they ask a question and give a critique. The participants, in this research, practiced a simulation about trauma-focused cognitive behavioral therapy and systemic therapy. To identify factors associated with completion of trauma-focused cognitive behavioral therapy TF-CBT conducted in a CAC resulted findings may suggest benefits of shortening the 6 years of age, treatment completion was related to younger child age (Celano et al., 2018). It is also in line with a study that describes protocol for the Systemic Therapy for At Risk Teens (START) trial, a multicenter UK-wide randomized controlled trial of multi-systemic therapy in antisocial adolescents at high risk of out-of-home placement that resulted the data about cost and clinical effectiveness of usual services provided to youth with serious antisocial behavioral problems (Fonagy et al., 2013).

The participants, in this study, practiced a simulation using website to recover children abuse victims. It is in line with a study using the Internet-Based Interacting Together Every day, Recovery After Childhood TBI (I-InTERACT) that involves parents of children ages 3 until 9 who support a moderate or severe traumatic brain injury any time since birth showed that increasing positive parenting behaviors, and decreasing negative parenting behaviors, parental distress, and children behavior problems (Narad et al., 2017). It is also in line with a study to test how the randomized controlled trial (RCT) and implementation study groups of the Strongest Families Smart Website (SFSW) intervention is distinguished in child psychopathology, family demographics and treatment-related factors. The results are that demographic factors or duration of behavioral problems dissimilar statistically or clinically between the RCT and implementation groups; and Parents in both groups informed a high level skills' satisfaction and professionalism of the telephone coaches (Ristkari et al., 2019).

In this study, the participants practiced a simulation of home visit to recover child abuse victims. It is in line with Casillas, Fauchier, Derkash, \& Garrido (2016) in their study about reviewing 156 studies incorporated with 9 distinguished home visitation program focused on caregivers of children between the ages 0 up to 5 revealed result that many factors of implementation home visits comprising training, supervising, and monitoring had a significant effect on program outcomes, especially child maltreatment outcomes. It is also in line with a study conducted by Vitale, Squires, Zuckerbraun, \& Berger (2010) about CPS caseworkers and child abuse physicians' (CAP) recommendation about the needs for medical evaluation of contact children and it resulted that it needs home visit as decision making process of caseworkers and it has a role to substitute a medical evaluation. So, home visits of caseworkers is effective method as decision making process as substitution of a medical evaluation. 


\section{Conclusion}

Children as victims need appropriate treatment based on the condition of them and such six treatments as a choice and solution to solve the recover the victims needs to implement professionally to manage the victims and gives no side effects. Previous studies indicated that Combined Parent-Child Cognitive Behavioral Therapy (CPC-CBT), Parent Training and Multi-systemic Therapy, Project Support (Children's Protective Services), Webbased parenting skills, Home Visiting Program, and School Based Mental Health Intervention for Children are effective to take care child abuse victims; therefore, they are recommended to be able to be used for children treatment.

\section{Acknowledgement}

The writer states great gratitude to Rector of Universitas Slamet Riyadi as the opportunity given to him for writing the present article. He is grateful to the Government of Sragen Regency for the support in this article. He states thank you to his colleague, Mr. Luqman Al Hakim for his suggestion in writing this article. Finally, He conveys his gratitude to all colleagues and students of Universitas Slamet Riyadi for motivation and support in writing the article.

\section{References}

Afifi, T. O., Mota, N. P., Dasiewicz, P., MacMillan, H. L., \& Sareen, J. (2012). Physical punishment and mental disorders: Results from a nationally representative US sample. Pediatrics, 130(2), 184-192. https://doi.org/10.1542/peds.2011-2947.

Akmatov, M. K. (2011). Child abuse in 28 developing and transitional countries-results from the multiple indicator cluster surveys. International Journal of Epidemiology, 40(1), 219-227. https://doi.org/10.1093/ije/dyq168.

Biçakçi, M. Y., Er, S., \& Aral, N. (2016). An overview of child neglect and abuse: Types, causes, impact and prevention. Studies on Ethno-Medicine, 10(2), 221-228. https://doi.org/10.1080/09735070.2016.11905491.

Casillas, K. L., Fauchier, A., Derkash, B. T., \& Garrido, E. F. (2016). Implementation of evidence-based home visiting programs aimed at reducing child maltreatment: A meta-analytic review. Child Abuse and Neglect, 53, 64-80. https://doi.org/10.1016/j.chiabu.2015.10.009.

Celano, M., NeMoyer, A., Stagg, A., \& Scott, N. (2018). Predictors of Treatment Completion for Families Referred to Trauma-Focused Cognitive Behavioral Therapy After Child Abuse. Journal of Traumatic Stress, 31(3), 454-459. https://doi.org/10.1002/jts.22287.

Chan, L., Erlings, E., Mizunoya, S., \& Zaw, H. (2016). A City Fit for Children : Mapping and Analysis of Child Friendly Cities Initiatives. Centre for Rights and Justice Occasional Paper Series, 5.

Damm, A. (2011). Mahatma Gandhi and Character Education in Non-Violence: Its Relevance in Religious Studies Today. Teaching Theology and Religion, 14(1), 3-12. https://doi.org/10.1111/j.1467-9647.2010.00667.x.

Dendape, G. A. R., Frederik, W. A. P. G., Mawuntu, J. R., \& Senewe, E. V. T. (2019). The Impact of Psychological Violence on Children and Legal Protection Efforts in Indonesia. Journal of Law, Policy and Globalization, 82, 82-91. https://doi.org/10.7176/jlpg/82-11.

Farnia, V., Salemi, S., Mordinazar, M., Khanegi, M., Tatari, F., Golshani, S., Jamshidi, P., \& Alikhani, M. (2020). The effect of child-abuse on the behavioral problems in the children of the parents with substance use disorder: Presenting a model of structural equations. Journal of Ethnicity in Substance Abuse. 
https://doi.org/10.1080/15332640.2020.1801547.

Fonagy, P., Butler, S., Cottrell, D., Scott, S., Pilling, S., Eisler, I., Fuggle, P., Kraam, A., Byford, S., Wason, J., Smith, J. A., Anokhina, A., Ellison, R., Simes, E., Ganguli, P., Allison, E., \& Goodyer, I. M. (2020). Multisystemic therapy versus management as usual in the treatment of adolescent antisocial behaviour (START): 5-year follow-up of a pragmatic, randomised, controlled, superiority trial. The Lancet Psychiatry, 7(5), 420-430. https://doi.org/10.1016/S2215-0366(20)30131-0.

Fonagy, P., Butler, S., Goodyer, I., Cottrell, D., Scott, S., Pilling, S., Eisler, I., Fuggle, P., Kraam, A., Byford, S., Wason, J., \& Haley, R. (2013). Evaluation of multisystemic therapy pilot services in the Systemic Therapy for At Risk Teens (START) trial: Study protocol for a randomised controlled trial. Trials, 14(1), 1-19. https://doi.org/10.1186/1745-6215-14-265.

Grogan-Kaylor, A. (2004). The effect of corporal punishment on antisocial behavior in children. Social Work Research, 28(3), 153-162. https://doi.org/10.1093/swr/28.3.153

Henggeler, S. W., \& Schaeffer, C. M. (2016). Multisystemic Therapy(®) : Clinical Overview, Outcomes, and Implementation Research. Family Process, 55(3), 514-528. https://doi.org/10.1111/famp.12232.

Jouriles, E. N., McDonald, R., Rosenfield, D., Norwood, W. D., Spiller, L., Stephens, N., Corbitt-Shindler, D., \& Ehrensaft, M. (2010). Improving Parenting in Families Referred for Child Maltreatment: A Randomized Controlled Trial Examining Effects of Project Support. Journal of Family Psychology, 24(3), 328-338. https://doi.org/10.1037/a0019281.

Khoeriyah, N., Warto, \& Sariyatun. (2018). Learning history integrated local wisdom values " babad Banyumas " to build a student 's national identity. 00091, 1-6. https://doi.org/https://doi.org/10.1051/shsconf/20184200091.

Markham, A. (2018). A Review Following Systematic Principles of Multisystemic Therapy for Antisocial Behavior in Adolescents Aged 10-17 Years. Adolescent Research Review, 3(1), 67-93. https://doi.org/10.1007/s40894-017-0072-1.

Mast, J. E., Antonini, T. N., Raj, S. P., Oberjohn, K. S., Cassedy, A., Makoroff, K. L., \& Wade, S. L. (2014). Web-based parenting skills to reduce behavior problems following abusive head trauma: A pilot study. Child Abuse and Neglect, 38(9), 14871495. https://doi.org/10.1016/j.chiabu.2014.04.012.

Narad, M. E., Taylor, H. G., Yeates, K. O., Stancin, T., Kirkwood, M. W., \& Wade, S. L. (2017). Internet-based Interacting Together Everyday, Recovery After Childhood TBI (I-InTERACT): Protocol for a multi-site randomized controlled trial of an internetbased parenting intervention. Digital Health, 3, 205520761771942. https://doi.org/10.1177/2055207617719423.

O'Leary, P., Coohey, C., \& Easton, S. D. (2010). The Effect of severe child sexual abuse and disclosure on mental health during adulthood. Journal of Child Sexual Abuse, 19(3), 275-289. https://doi.org/10.1080/10538711003781251.

Ristkari, T., Kurki, M., Suominen, A., Gilbert, S., Sinokki, A., Kinnunen, M., Huttunen, J., McGrath, P., \& Sourander, A. (2019). Web-based parent training intervention with telephone coaching for disruptive behavior in 4-year-old children in real-world practice: Implementation study. Journal of Medical Internet Research, 21(4), 1-17. https://doi.org/10.2196/11446.

Rogers, J. C., \& Broome, M. R. (2020). Effectiveness of multisystemic therapy for adolescent antisocial behaviour: follow-up findings from the START trial. The Lancet Psychiatry, 7(5), 375-376. https://doi.org/10.1016/S2215-0366(20)30167-X.

Rueness, J., Myhre, M. C., Strøm, I. F., Wentzel-Larsen, T., Dyb, G., \& Thoresen, S. (2019). 
The mediating role of posttraumatic stress reactions in the relationship between child abuse and physical health complaints in adolescence and young adulthood. European $\begin{array}{lll}\text { Journal of Psychotraumatology, } & \text { 10(1). }\end{array}$ https://doi.org/10.1080/20008198.2019.1608719.

Ruiz-Casares, M., Lilley, S., Thombs, B. D., Platt, R. W., Scott, S., Isdijoso, W., Hermanus, E., Andrina, M., \& Mayo, N. (2019). Protocol for a cluster randomised controlled trial evaluating a parenting with home visitation programme to prevent physical and emotional abuse of children in Indonesia: The Families First Programme. BMJ Open, 9(1), 1-12. https://doi.org/10.1136/bmjopen-2018-021751.

Runyon, M. K., Deblinger, E., \& Steer, R. A. (2010). Group cognitive behavioral treatment for parents and children at-risk for physical abuse: An initial study. Child and Family Behavior Therapy, 32(3), 196-218. https://doi.org/10.1080/07317107.2010.500515

Springer, C., \& Misurell, J. R. (2012). Game-based cognitive-behavioral therapy individual model for child sexual abuse. International Journal of Play Therapy, 21(4), 188-201. https://doi.org/10.1037/a0030197.

Taillieu, T. L., Cheung, K., Sareen, J., Katz, L. Y., Tonmyr, L., \& Afifi, T. O. (2019). Caregiver Vulnerabilities Associated With the Perpetration of Substantiated Child Maltreatment in Canada: Examining the Canadian Incidence Study of Reported Child Abuse and Neglect (CIS) 2008. Journal of Interpersonal Violence, 1-29. https://doi.org/10.1177/0886260519889941.

Tol, W. A., Komproe, I. H., Jordans, M. J. D., Ndayisaba, A., Ntamutumba, P., Sipsma, H., Smallegange, E. S., Macy, R. D., \& De Jong, J. T. V. M. (2015). School-based mental health intervention for children in war-affected Burundi: A cluster randomized trial. Childhood Adversity and Developmental Effects: International and CrossDisciplinary Perspectives, 271-295. https://doi.org/10.1201/b18372.

Tsur, N., \& Abu-Raiya, H. (2020). COVID-19-related fear and stress among individuals who experienced child abuse: The mediating effect of complex posttraumatic stress disorder. Child Abuse and Neglect, July, 1-11. https://doi.org/10.1016/j.chiabu.2020.104694.

Vitale, M. A., Squires, J., Zuckerbraun, N. S., \& Berger, R. P. (2010). Evaluation of the siblings of physically abused children: A comparison of child protective services caseworkers and child abuse physicians. Child Maltreatment, 15(2), 144-151. https://doi.org/10.1177/1077559509360250.

Yoon, D. (2020). Peer-relationship patterns and their association with types of child abuse and adolescent risk behaviors among youth at-risk of maltreatment. Journal of Adolescence, $\quad$ 80(September 2019),

$125-135$. https://doi.org/10.1016/j.adolescence.2020.02.008. 